\section{LITERATURA LATINO-AMERICANA DO SÉCULO XX E "PÓS-ESTRUTURALISMOS": UM OLHAR COMPARATIVISTA}

\section{MCGUIRK, Bernard. Latin American literature: symptoms, risks and strategies of poststructuralist} criticism. London \& New York: Routledge, 1996. 265 p.

É oportuno resenhar, neste número especial da Revista de Estudos de Literatura que versa sobre a América Latina, o novo lançamento da Editora Routledge, recém-saído da gráfica, de autoria do renomado detentor da cátedra de Literaturas em Línguas Românicas e Teorias Críticas da Universidade de Nottingham, Bernard McGuirk, que oferece ao público sua contribuição sobre a literatura latino-americana do século XX. Por se tratar de livro surpreendente, que associa um estilo lúdico e criativo a um manuseio profundo das teorias críticas contemporâneas na análise de uma gama diversificada e atual das literaturas latino-americanas, prevê-se que ele integrará a biblioteca de referências básicas para especialistas nessas literaturas e culturas, constituindo também um desafio instigante para o público leitor em geral. Trata-se, ainda, de livro de importância capital para críticos e especialistas em Literatura Comparada. Os comparativistas certamente apreciarão a ampliação das fronteiras textuais e semióticas através de enriquecedoras interligações da literatura com o cinema, a mídia e a música popular, como também os benefícios advindos do seu engajamento com tradições literárias diversas e com as linhas críticas conflitantes que sempre emergem de dentro das fronteiras nacionais e institucionais.

Aqueles que já conhecem as atividades literárias e projetos culturais do Professor McGuirk no Brasil e, dentre os vários contextos hispano-americanos, notadamente na Argentina, reconhecerão no livro as qualidades inerentes ao autor
— um profundo domínio da teoria crítica contemporânea e uma sutil e meticulosa análise textual, ambos entrelaçados a uma escrita original e "subversivamente" experimental.

Sobre o autor, cumpre ressaltar, ainda mais, sua formação pós-graduada na Universidade de Oxford e, dentre sua rica experiência docente, o magistério na Ecole Normale Supérieure de Paris, onde compartilhou de profícua convivência com Derrida e outros pensadores pós-estruturalistas franceses. Atuou também como professor visitante em diversas instituições, dentre elas a Universidade de Michigan em Ann Arbor. Na sua ampla atividade de pesquisa, destaca seu trabalho sobre as minorias urbanas, na qualidade de pesquisador no âmbito do Projeto Rockefeller (CIEC - Rio de Janeiro, 1995) e atividades análogas na Fundação Memorial da América Latina (São Paulo). Mais especificamente, refiro-me ao projeto integrado de pesquisa, docência e publicação, a partir de 1992, sobre as transferências interculturais, intitulado "A interface entre os estudos críticos e culturais - Convênio UFMG/ Nottingham", sob os auspícios da CAPES e do Conselho Britânico, cuja coordenação com ele compartilho e que se triangula com a Universidade Nacional de Córdoba.

A necessidade, por ele percebida e explicitada na Introdução ao livro, de se inter-relacionar pós-estruturalismos e histórias e de se elaborar um mosaico de teorias culturais e métodos de identificação de práticas críticas específicas, leva o autor a perguntar, ecoando Guimarães Rosa, "posso tomar o seu lugar?". E conclui que "a literatura realça as diferenças que os Estudos Culturais exploram" (p.19). Desvelando também o potencial de a literatura e a teoria se interpelarem mutuamente nos seus limites e limitações, arriscando ("taking risks"), Bernard McGuirk utiliza estratégias que desvelam as diferenças sintomáticas entre e dentro das culturas latino-americanas, a partir de textos de Jorge Luis Borges, César Vallejo, Rubén Darío, Pablo Neruda, Mário de Andrade, Guimarães Rosa, Julio Cortázar, Carlos Fuentes a Susana Thénon, dentre outros. 
Ao analisar as relações e tensões entre teoria e história, entre a crítica literária e os Estudos Culturais, entre "novos historicismos" e "hibridismos", entre "pósestruturalismos" e "pós-modernismos", McGuirk busca politizar seus argumentos, situando-os em contextos ideológicos específicos. É nesse sentido que o autor confronta seu próprio locus de enunciação ao investigar uma gama expressiva de literaturas - dentre outras, do Brasil, Argentina, Chile, Guatemala, México, Nicarágua e Peru. Sua nem sempre confortável posição de teórico e crítico numa tradição britânica e pragmática, lançando seu olhar subversivo à tão diversa produção literária latino-americana, cada uma revestida de uma acentuada especificidade, torna-se evidente já na Introdução. Problematizando também, como é de se esperar, seu próprio objeto de análise, a América Latina - "uma utopia ou uma atopia? um projeto ou uma projeção?" - , pois "para muitos latino-americanos não há tal lugar e nem tampouco uma literatura comum" (p.XI), argumenta que a ênfase na diferença ou diferenças entre países e culturas não é apenas literária, daí a necessidade de se contemplarem os encontros culturais específicos que, segundo o autor, são sempre ideológicos. $O$ entrelaçamento entre literatura, teorias críticas e estudos culturais perpassa, assim, a tessitura do livro e o estudo das diferenças entre e dentro das culturas ditas latino-americanas:

Optei por refletir sobre a diferença entre o simples rótulo de "Estudos Culturais" e o penoso compromisso intelectual implícito na efetiva análise de culturas específicas, devido ao risco de se encarar o exercício da teoria crítica como antagônico ao rastreamento de questões políticas e históricas... Mas os estudos culturais não são também estudos críticos?... Já a teoria crítica, pelo menos nas suas diversas modalidades praticadas neste livro, opera inseparavelmente da discursividade da expressão cultural (p.14-15).

$\mathrm{Na}$ vasta trajetória percorrida pelo livro e delineada na Introdução, o autor apresenta também a proposta de subversão teórica e literária de dicotomias redutoras. Teoricamente, aborda, dentre outras, a contribuição do sociólogo argentino Francisco
Delich na reconceituação da dialética hegeliana do espaço público versus espaço privado como uma possível extensão do binarismo corpo e alma (p.12); discorre, também, sobre a lingüística do contacto de Mary Louise Pratt e sobre sua aproximação filosófica a diversos téricos brasileiros, como o pensamento de Haroldo de Campos ou a minha própria proposta teórica de uma estética tradutória pós-moderna que transcenda binarismos, como o fenômeno da dupla captura descrito por Deleuze (p.5-7). Conclui a Introdução enfatizando que o livro se propôe a explorar formas pelas quais a própria literatura latino-americana resiste a polarizações redutoras (p.29). Tal colocação se entrelaça ao "Post-postcript" ("Pós-postcript"), onde é adensada a reflexão sobre a América Latina e o "terceiro termo" e onde o autor revitaliza escritores, notadamente Guimarães Rosa, na apresentação de um discurso alternativo desse terceiro termo, alinhando-o a Einstein, Peirce, Bakhtin ou Levinas.

O capítulo 1 apresenta uma crítica do humanismo liberal através de leituras pré- e pós-estruturalistas da poesia lírica de Pablo Neruda, constituindo um brilhante exercício de análise textual. Aborda, igualmente, o papel da crítica literária de propiciar diferentes "prazeres do texto", preparando o campo para explorações extratextuais subseqüentes, mais especificamente das implicações ideológicas, de gênero, psicanalíticas, formalistas e histórico-culturais das diversas produções textuais pós-estruturalistas.

Suas perspectivas críticas, preponderantemente pós-estruturalistas, vão-se entrelaçando também, com naturalidade, ao pensamento de muitos críticos latinoamericanos contemporâneos, em linhas gerais, de formação intelectual pós-derridiana. Nesse sentido, o autor revela ampla

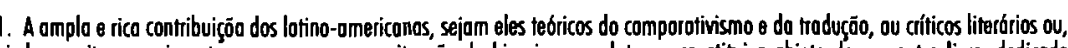
ainda, escritores e cineastos, pora umo reconceinuoģóo de binarismos redutores, constitui o objeto de um outro livo, dedicado especificamente ao "terceiro termo". Esse lançomento iminente do serrie Nottinghom Monographs in the Humanities, intitulado Retranslating Latin Americo: dimensions of the third term, editada por Bernord McGuirk \& Else Ribeiro Pires Vieiro (Nottinghom:

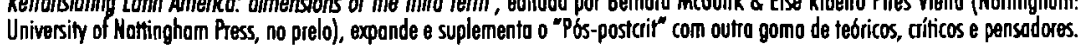


familiaridade com os debates no Brasil e América Hispânica, ao mesmo tempo em que incorpora a suas reflexões pensadores como Silviano Santiago, Haroldo de Campos, Roberto Schwarz, Nicolau Sevcenko e os já renomados comparativistas da Universidade Federal de Minas Gerais. É de se observar o destaque conferido aos críticos brasileiros, o que é raro dentre os estudiosos da América Latina no circuito internacional, que tendem a privilegiar os pensadores hispano-americanos. Todavia, McGuirk projeta essas contribuições em terrenos comparativos não familiares. É este o caso de um capítulo que focaliza especificamente o Brasil, o Modernismo, a exotização, o olhar masculino e a construção do Outro de fora e de dentro ("Eurocentrism and the male gaze in Brazil: other place, other plays: the ploy of alterity in Blaise Cendrars' South Americans"). O autor observa, através da visão que Cendrars tem do Brasil, os aspectos problemáticos de Oswald de Andrade, Manuel Bandeira, Mário de Andrade, Carlos Drummond de Andrade e, retrospectivamente, da construção de Ernst Jandl da mulher nem tanto como "Sud-américaines" mas como "pseudo-américaines" (p.49). A aproximação fonológica de "Sud" $/$ "pseudo" localiza a diferença, o que remete ao próprio subtítulo da Introdução (Locating Inequality: Post-, Trans-, Intra-).

O capítulo 3, sobre a meta-história da literatura, contrapõe o "modernismo" e a "modernidad", enfocando a poética da descontinuidade, através de análises de Rubén Darío e César Vallejo. Mais especificamente, o autor procura problematizar a visão de a História Literária ser tão suscetível quanto a própria História a tropos acentuadamente discursivos, como nas análises de Hayden White. Enfatizando a metadimensão das tentativas de construção da continuidade através dos "-ismos" dos sucessivos movimentos literários, ele se respalda, por exemplo, em Barthes e Foucault para contrapor o espaço das descontinuidades (p.68).

Rubén Darío e César Vallejo são retomados, desta feita, para uma discussão da intertextualidade e da resistência à modernidade ("Reading, misreading and the resistance to modernity: on misprision and intertextuality from Rubén Darío to César Vallejo"). Em minuciosa aplicação dos conceitos de Harold Bloom em Ansiedade da influência, ele compara Mallarmé e Vallejo. Situando-se na crítica psicanalítica, contesta a teoria da influência calcada na visão da normalidade da aceitação de precedentes e precursores, substituindo a luta angustiada contra a "prioridade" pela luta contra a "paternidade" (p.58). O autor aborda, também, a partir de Trilce (de Vallejo), o experimentalismo intelectual e formal de uma arte pósmoderna revolucionária e uma insatisfação, herdada de Darío, com a própria écriture ou com as limitações da écriture (p.8793).

Vallejo é novamente retomado no capítulo seguinte, ensejando uma discussão teórica ("Poetry, pedagogy and untranslatability: on écriture and oralité in two poems of César Vallejo's Trilce"). Nele são descontruídas as quatro modalidades tradicionais da crítica literária identificadas por Todorov. Em seguida, o autor reflete sobre as limitações do estruturalismo através de uma "performance" desconstrutora em contraposição a Vallejo (p.107-114). Discute também a emergência da oralidade na poesia moderna, explorando, através de Wittgenstein, paralelos da intraduzibilidade, da poética e teorias críticas.

O sério e o lúdico se entrelaçam quando McGuirk "vai ao encalço" de teorias, como a do argentino Piglia, da ficção detetivesca como meta-crítica, ou dos ecos de Lyotard em Piglia detectados por Eneida Maria de Souza; ela, todavia, segundo o autor, de forma perceptiva, aponta a especificidade latinoamericana da proposta literária do argentino, como evidencia a citação por ele feita desta teórica e crítica, ao conferir às histórias parapoliciais o estatuto ambivalente de teoria e ficção, para denunciar o mito da escrita pura e inocente (p.123). Aqueles não familiarizados com o estilo pós-moderno da crítica do autor não devem se surpreender com o amálgama de intelectualismo 
e tratamento anárquico ao elaborar, especificamente, a apropriação hollywoodiana da violência erudita borgiana. Ademais, nenhuma oportunidade é perdida na exploração das implicações ideológicas e culturais da intertextualidade: "o que reside num texto é sempre uma função do que o leitor, o espectador, pode (de forma palimpséstica) sobrepor" (p.13637). Subversivamente, ele aborda, através desse estilo hollywoodiano de apropriações de Borges, as epistemologias pós-modernas de Death and the Compass e de Dick Tracy, arrolando Madonna e Warren Beatty nas fileiras de leitorescríticos praticantes. ${ }^{2}$

Um título que entrelaça a Semiótica e a "Semierótica" da alteridade associáveis a El otro cielo de Cortázar ("On the semi(er)otics of alterity: beyond Lacanian limits: Julio Cortázar's The other heaven") confere destaque aos desconcertantes e ricos jogos de palavras que constituem a marca registrada da fertilidade crítica do Professor McGuirk (um manuseio lúdico da palavra e um sobrenome celta que apontam para essa tradição irlandesa, que já aprendemos a admirar em James Joyce ou Oscar Wilde). Abordando Cortázar através de perspectivas pós-lacanianas e de contribuições recentes de Derrida, lendo a inseparabilidade da performance psico-sexual e econômico-ideológica da dupla Buenos Aires - Paris (p. 143), o autor explora o que considera serem imaturidades do nacionalismo, lançando a sombra dos Espectros de Marx de Derrida sobre o texto desse argentino.

É de se lamentar que o jogo fonológico detectável na rima do título do proximo capítulo ("Mirror X scissors: reflections on cuts from Carlos Fuentes' Terra Nostra") se perca na possível tradução "Espelho X Tesouras". É de se admirar, todavia, que a tradução permita a manutenção da riqueza do jogo gráfico e semântico contido no " $X$ " do título: uma 2. A brilhonte troduşäo de Myriom Ávila deste copítula especílico ("Beyond structural influence: Barges and the purloined detective:

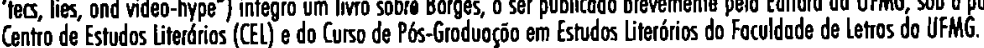

representação visual da tesoura no proprio texto de Fuentes, mas também versus, uma releitura de Fuentes contra a teoria do reflexo. Utilizando e, ao mesmo tempo, sub-vertendo o "espelho" (também retirado do próprio texto de Fuentes), McGuirk questiona os "pontos cegos" de inadequadas aplicações da crítica marxista nas práticas pós-estruturalistas. Por outro lado, compartilha com Foucault a proposta de desarraigar fundamentos tradicionais, respondendo à colocação deste teórico de que o conhecimento é feito para ser cortado e não compreendido (p.170), utilizando também incisões feitas em textos de Derrida, Borges, Mauss e Eagleton, para demonstrar que a desconstrução não tem outra alternativa senão aplicar a tesoura às representações da história.

O entrelaçamento da subjetividade, da história e da ideologia se faz na sua leitura da re-localização do Eu em "Borges y yo" através do filtro de Adorno. Ele argumenta que o pós-estruturalismo e o pós-marxismo necessariamente não se rivalizam. Situando as reflexões de Borges no que Paul Smith denomina "o sujeito ideológico", ele resgata esse argentino das acusações de textualismo hermético e de auto-complacente jogo de palavra (p.184). $O$ trânsito fácil com as diversas nuances do intelecto irrequieto e especulador desse visionário cego de Buenos Aires novamente se evidencia no capítulo 10 ("Z/Z: on midrash and écriture féminine in Jorge Luis Borges' 'Emma Zunz"'). Reaparecem nesse capítulo os instigantes jogos de palavras, sutilmente usados para ilustrar e ampliar nosso entendimento da escritura feminina. Lendo "Emma Zunz" no contexto dos discursos de oposição ao fascismo anti-semita, ele utiliza também discursos críticos radicalmente alternativos para especular sobre as práticas feministas e seus "pontos cegos". Refiro-me, especificamente, ao original perfilar do pensamento judaico na trama do discurso literário na sua leitura do texto de Borges juntamente com a hermenêutica judaica midrashica.

A Argentina é contemplada também em um capítulo que notadamente evidencia a associação crítica do 
subversivo ao lúdico. Apropriando-se da Ova completa de Susana Thénon (1987), ele "quebra os ovos" da ilusória plenitude discursiva, literária e crítica. Através das "Coreografias" de Derrida e de "O tempo da mulher" de Kristeva, ele contempla a possibilidade de que a metafísica ocidental dance de outra forma, por exemplo, como na crítica contida no poema de Thénon às expressões sexuais, sociais e "torturantemente" políticas na Argentina. A análise da dimensão política revela também estar o autor bastante atualizado com os discursos pós-ditadura argentina que a poesia de Thénon explora, não permitindo, todavia, que a leveza de seu toque crítico se submerja ao tour de force performático dos textos propositalmente ousados de Thénon. Não constitui um paradoxo o fato de Thénon ter no crítico McGuirk um celta disposto a ouvir e a "acolher em sua própria casa" a sua dupla interpelação, no contexto pós-guerra das Malvinas, do intra-colonialismo anglo-saxão (na linha da então primeira-ministra inglesa, Margaret Thatcher) $e$ argentino (do então presidente Galtieri) (p.230-32). Assim, as trajetórias da poeta e do crítico parecem convergir para uma subversividade construtiva.

Merece destaque o sutil entrelaçamento no "Póspostcript" ("Post-postcript") de textos do guatemalteco Augusto Monterroso, de Ángel Rama, de Guimarães Rosa, do mexicano Juan Rulfo e de músicas de Caetano Veloso com uma série de reflexões teóricas dentro, fora e além da tradição greco-romana. Ele faz ressurgir também as apropriações portuguesas do Outro - medievais, renascentistas e do início da era moderna, incluindo Camões e Fernando Pessoa - e, desde então, dos espaços latino-americanos.

Como dito, no "Pós-postscript", o autor adensa a proposta do livro, delineada teoricamente na Introdução, de subversão de binarismos redutores, explorando o papel da literatura latino-americana na resistência a polarizações e revitalizando escritores, notadamente Guimarães Rosa, que apresentam um discurso alternativo desse terceiro termo.

As margens de um rio, explicitadas como a "quintessência do binarismo, em termos referenciais... devem ainda encontrar uma outra mensurabilidade, uma relatividade", textualizada por Guimarães Rosa, segundo o autor, "em três termos, 'o rio-rio-rio", ou, por sua "introdução da kinesis da instabilidade" em "'rio abaixo, rio a fora, rio a dentro", ou pela intervenção, antes do perdão - o termo ausente - do “triplo ecoar 'pedindo', 'pedindo', 'pedindo"” (p.248-49).

Escrever é sempre reescrever, que não difere da citação - a conhecida colocação de Compagnon que me transporta para o prazer do texto reescrito. Lendo, reescrevendo, citando minhas reflexões teóricas sobre a tradução enquanto espaço terceiro, enquanto "(w)rite of passage", a partir da explicitação da trans-historização latente na estória "Sequiência" de Rosa ${ }^{3}$, McGuirk suplementa o meu texto com as colocações de Bennington sobre a cumplicidade que permitiu ao estruturalismo coabitar com a história. ou sua própria nomeação de uma tradução interlingual e percepção de uma economia libidinal no texto rosiano.

Retomando o estilo experimental e a dimensão visual da sua escrita, o autor apresenta um mosaico de citações teóricas justapostas sobre o discurso do terceiro termo compondo o mosaico, Irigaray, Derrida, Levinas, Bennington, Taylor. Um mosaico gráfico que se verbaliza, na conclusão do livro, através da metáfora da colcha de retalhos, por ele entendida como uma cobertura "aconchegante"/"acolchegante" de um espaço, continuamente expandível.

Para concluir a difícil tarefa de resenhar um livro que a cada momento se expande, situando-se, num eco derridiano, na fronteira impossível do constante transformar de escritas/reescritas, cito, dentre outros textos latino-americanos 
analisados no "Pós-postscript", parte de sua leitura pósestruturalista, na música de Caetano Veloso, da figura de Clarisse,

a beleza assombrante de cujo gesto não consegue mascarar, de fato expõe, uma economia libidinal (...) do sistema do Outro de autoridade (coercitiva) e da propensão pós-estruturalista 'de atuar como uma depuração das limitações desse sistema' (p.151).

O que esta resenha pode sugerir, como conclusão, é a tradução do livro para o português e espanhol, antecipando, também, que brevemente surgirão inúmeras respostas a ele.

Else Ribeiro Pires Vieira

UFMG 